\title{
Liquid-phase sintering of lead borosilicate glass-alumina composite
}

\author{
K. P. KUMAR, R. RAMESH*, K. SESHAN
}

Faculties of Chemical Technology and * Mechanical Engineering, PO Box 217, 7500 AE, University of Twente, Enschede, The Netherlands

V. C. S. PRASAD

Materials Development Department, Bharat Electronics Ltd, Bangalore, India

In the past few years there has been a search for suitable low-temperature-sinterable alumina-based compositions which could be cofired with other dielectric materials and pastes for use in multilayer hybrid microcircuit substrate applications [1]. Glass-ceramic materials having low dielectric constants and which could be sintered at $900^{\circ} \mathrm{C}$ in air or in a neutral atmosphere have been suggested [2]. The advantages of sintering in the presence of a liquid phase have long been recognized in both powder metallurgy and ceramics [3-7].

Glass powder of the following composition was used for the present study: (wt \%) 65.18 PbO, 20.13 $\mathrm{B}_{2} \mathrm{O}_{3}, 13.02 \mathrm{SiO}_{2}$ and $1.67 \mathrm{Al}_{2} \mathrm{O}_{3}$. Details of glass powder preparation are reported elsewhere [8]. The composite was prepared as follows. A mixture of $55 \mathrm{wt} \%$ alumina and $45 \mathrm{wt} \%$ glass was first ball milled for $10 \mathrm{~h}$ in water medium using zirconia balls in a polyethylene container. The dried composition was mixed with $3 \%$ PVA as binder and granulated. Pellets were made from -60 to +200 mesh fraction of these granules. Discs of $15 \mathrm{~mm}$ of $15 \mathrm{~mm}$ diameter and $4 \mathrm{~mm}$ thickness were pressed with a pressure of $100 \mathrm{MPa}$. The discs were sintered in air for a duration of $210 \mathrm{~min}$ at temperatures ranging from 900 to $1100^{\circ} \mathrm{C}$. A typical sintering schedule is given in Fig. 1. Diametrical shrinkages of more than 250 samples were measured. XRD and SEM studies were carried out in a Philips Diffractometer Model No. PW 1710 and Camscan Cambridge System, respectively.

The XRD patterns of the glass-alumina composites sintered at different temperatures are shown in Fig. 2. Peaks marked $E$ do not appear in pure alumina. They

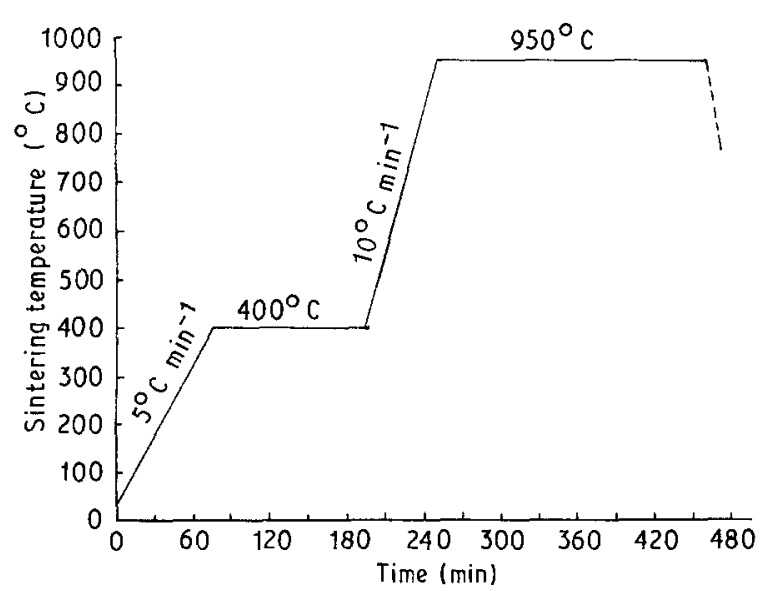

Figure I A typical sintering schedule for the glass-alumina composites. even appear in compositions heated to $900^{\circ} \mathrm{C}$ and are due to the reaction between the glass and alumina. Intensity of these new peaks, $\mathrm{E}$, gradually increases up to $1000^{\circ} \mathrm{C}$ indicating the extent of the reaction. Above $950^{\circ} \mathrm{C}$, considerable peak shift can be noticed. At $1050^{\circ} \mathrm{C}$ the intensities of all the peaks have drastically decreased showing reduction in the crystalline phase.

The variation of diametrical shrinkage as a function of sintering temperature is shown in Fig. 3. It can be observed that, initially, shrinkage increases with sintering temperature and reaches a maximum around $1000^{\circ} \mathrm{C}$, and then decreases. The process is essentially liquid-phase sintering. The viscosity of the liquid glass formed decreases with increasing temperature, which in turn enhances densification due to the surface tensional rearrangement [3].

Figs $4 \mathrm{a}$ and $\mathrm{c}$ show a schematic representation of the green compact and the composite sintered at $1000^{\circ} \mathrm{C}$, respectively. The densification in this case is mainly due to particle rearrangement. The average particle size of the alumina powder (RC 172, Renold's Co., USA) was $0.65 \mu \mathrm{m}$. Each particle therefore consisted of only one crystallite and hence the secondary rearrangement through grain boundary penetration by the liquid and particle disintegration is nonexistent in this case [9]. The following are the factors contributing to the decrease in shrinkage after $1000^{\circ} \mathrm{C}$ :

(a) The increase in temperature which increases alumina dissolution in glass [10]; this can be seen from the XRD pattern (Fig. 2). As a result of this, the viscosity of the liquid glass increases, which slows down the initial rearrangement due to capillary pull.

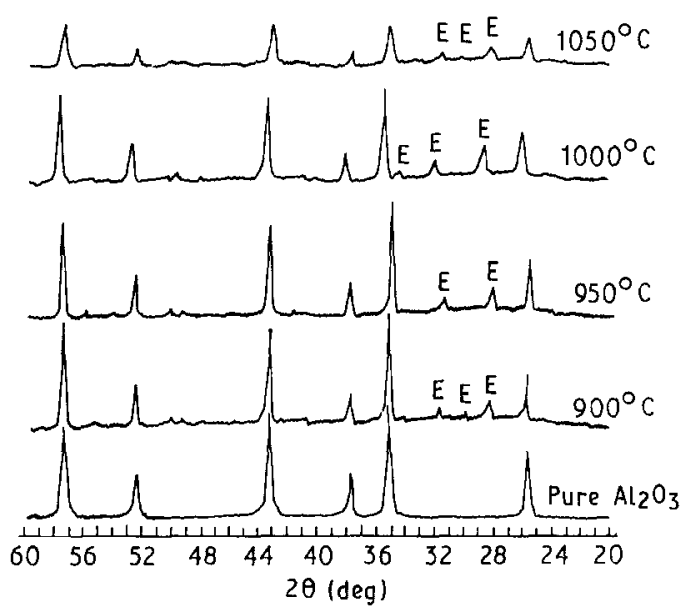

Figure 2 XRD patterns of pure alumina and glass alumina composites heated at different temperatures. 


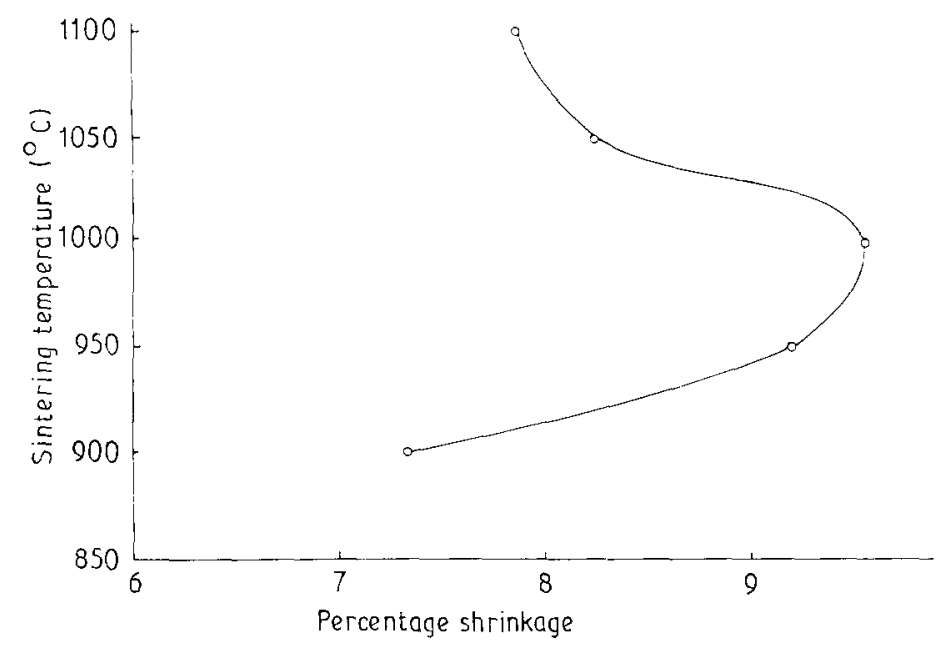

Figure 3 Diametrical shrinkage plotted against sintering temperature for glass-alumina composites.
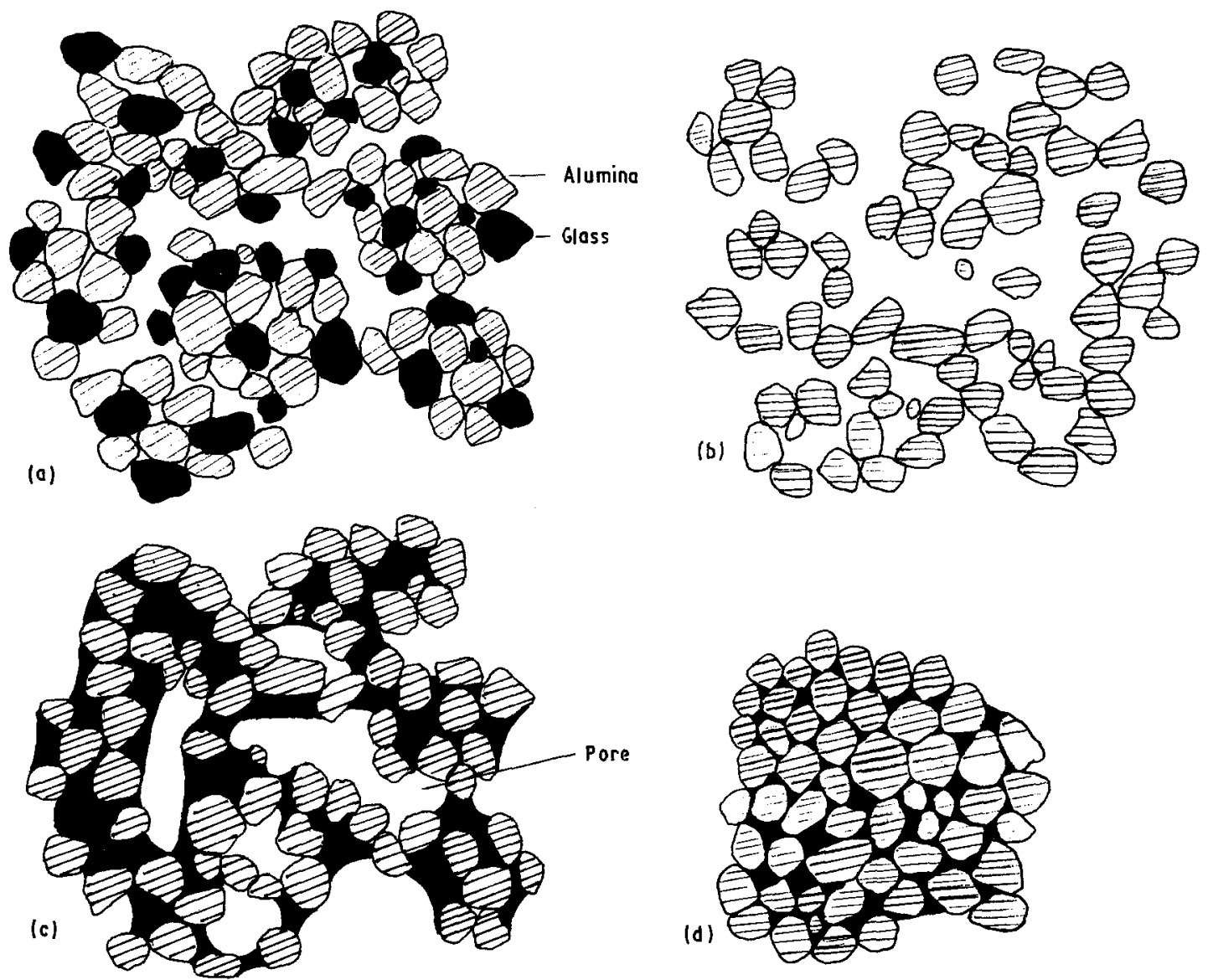

Figure 4 Schematic representation of the sintering process: (a) green glass-alumina composite, (b) skeleton structure of alumina without glass particles, (c) less densified structure, partially due to early onset of solid solid neck formation, and (d) well-densified structure.

(b) The early onset of the solid-solid contact, which forms the alumina network (Fig. 4b), at higher temperatures, slows down the densification due to rearrangement (Fig. 4d) [11]. Moreover, solid skeleton fragmentation is difficult due to the very high viscosity of the alumina-rich, liquid-glass phase.

There is a greater amount of glassy phase above $1000^{\circ} \mathrm{C}$ (Fig. 2) and the glassy phase is usually less dense than the crystalline phase. But in this case the contribution of the above factor to the lowering of densification above $1000^{\circ} \mathrm{C}$ is not appreciable because of the higher density of the glass $\left(4.2 \mathrm{~g} \mathrm{~cm}^{-3}\right)$ compared to that of alumina $\left(2.9 \mathrm{~g} \mathrm{~cm}^{-3}\right)$.

Detailed microstructural investigations are in

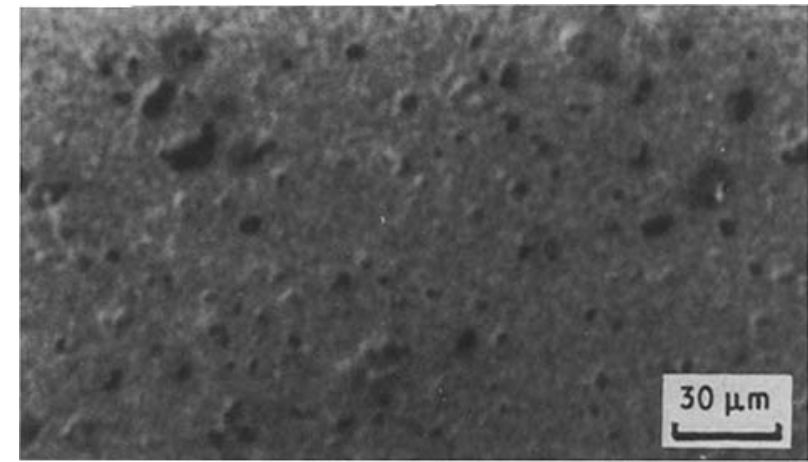

Figure 5 SEM micrograph of polished surface of the glass-alumina composite sintered at $1000^{\circ} \mathrm{C}$. 
progress with aluminas of different particle size in order to find out the mechanism of secondary rearrangement due to grain boundary penetration and particle disintegration. A typical polished-surface SEM micrograph of a sample sintered at $1000^{\circ} \mathrm{C}$ is given in Fig. 5.

\section{References}

1. H. TOSAKI, N. SUGISHITA and A. IKEGAMI, ISHM Proc., (1981) p. 100.

2. Y. SHIMADA, in Proceedings of the Annual Meeting of the Ceramic Society of Japan, (1982) p. 114.

3. W. D. KINGERY, J. Appl. Phys. 30 (1959) 301.

4. F. V. LENEL: "Powder Metallurgy Principles and Applications" (Metal Powder Industries Federation, New Jersey, 1980) p. 285.
5. R. M. GERMAN, "Liquid Phase Sintering" (Plenum, New York, 1985).

6. G. PETZOW and W. A. KAYSSER, in "Science of Ceramics", edited by H. Hausner (Deutsche Keramische Geseilschaft, Weiden, 1980) Vol. 10, p. 269.

7. S. PEJOVNIK, in "Sintering New Developments Materials Science Monographs" (Elsevier, New York, 1979) Vol. 4, p. 285.

8. K. P. K UMAR, submitted to Mater. Sci. \& Engng. (B).

9. T. H. COURTNEY, Met. Trans. 15A (1984) 1065.

10. P. PALANISAMY, D. H. R. SARMA and R. W. WEST, J. Am. Ceram. Soc. 68 1(985) C215.

11. BI-SHIOU, W.-Y. HSU and J.-G. DUH, Ceram. Int. 14 (1988) 7.

Received 7 July

and accepted 14 September 1989 